\title{
Aquatic Ecosystem and Biodiversity: A Review
}

\author{
Sufia Irfan*, Aishah Mohammed Motir Alatawi \\ Biology Department, Faculty of Science, College of Science, University of Tabuk, Tabuk, KSA \\ Email: *sirfan@ut.edu.sa, amm.alatawi@ut.edu.sa
}

How to cite this paper: Irfan, S. and Alatawi, A.M.M. (2019) Aquatic Ecosystem and Biodiversity: A Review. Open Journal of Ecology, 9, 1-13.

https://doi.org/10.4236/oje.2019.91001

Received: November 29, 2018

Accepted: January 28, 2019

Published: January 31, 2019

Copyright $\odot 2019$ by author(s) and Scientific Research Publishing Inc. This work is licensed under the Creative Commons Attribution International License (CC BY 4.0).

http://creativecommons.org/licenses/by/4.0/

\begin{abstract}
Aquatic ecosystems support a substantial source of the earth's biological diversity. They are an essential reservoir and share an enormous proportion of earth's biological productivity. Both aquatic resources and its biodiversity are interrelated to each other and they perform a myriad of functions and are valuable and essential for the sustainability of biotic communities. Aquatic biodiversity in both freshwater and marine environments are under continuous decline because of overexploitation of species, introduced exotic plant or animal, pollution sources from cities, industries and agricultural zones, loss and changes in ecological niche. Their conservation and management in the form of bio reserve points and bioregional management and worldwide monitoring are needed for the protection of the aquatic biodiversity. This review is presenting information on biodiversity in aquatic habitats and their resources, in marine and fresh water ecosystems, their importance conservation and restoration mechanisms.
\end{abstract}

\section{Keywords}

Aquatic Ecosystem, Biodiversity, Conservation, Restoration

\section{Introduction}

The Convention on Biological Diversity, describes "Biodiversity as the variations among all organisms". Biodiversity can be termed as the variations among living biota performing their ecological functions in the terrestrial marine and other freshwater ecosystems and the other ecological complexities where they are living such as intraspecific diversity, interspecific diversity and diverse biota in the ecosystems. Aquatic biodiversity is comprehensive term that comprises freshwater ecosystems with lakes, ponds, reservoirs, rivers, streams, groundwater, and wetlands. The other part of aquatic biodiversity has marine ecosystems, which makes up an ocean, estuaries, salt marshes, coral reefs, mangroves and algal colonies. Different kinds of phytoplanktons, zooplanktons, aquatic plants, insects, 
fishes, birds and mammals are also an important part of aquatic biodiversity.

Marine ecosystems are valuable wealth but vulnerable too. Extended sea and ocean water contributes about $90 \%$ of the marine ecosystem and shares about $10 \%$ of the total marine animals' population. Whereas freshwater resources occur in insignificant proportions comparison to other water systems on the earth and their distribution and usage are also not balanced [1]. Gleick [2] reported that surface freshwater habitats accounts for only $0.01 \%$ of the earth's water which is covering only about $0.8 \%$ of the globe surface.

Human life has closely been associated with the water bodies with various functions ever since the ancient times. Water reservoirs and aquatic biodiversity have intimate relationship and both the ecological units have interdependency on each other. Evaporation of surface water from the ocean has major role in continuation of water circulation from atmosphere-to-lithosphere. Ocean has a great capacity to transport heat from the earth, mitigation of severe natural calamities through its reciprocal interactions with atmosphere, providing optimum temperature for occurrence and growth of organisms. Oceans are significantly involved in the global weather conditions and climatic transitions. There is occurrence and growth of unique ocean life with variety of organisms present making it a diverse ecosystem. Recently, there is a great emphasis on the function between the ocean and the climate change. The ocean ecosystem not only stores a great amount of water but also absorbs plenty of carbon in the form of "carbon sink". Marine phytoplanktons are capable of processing annual net primary production of around 50 billion tons of carbon this amount is approximately equal to the primary production of terrestrial plants. Primary production turnovers are fast moving and the transportation of matters is highly active.

Primary producers of the oceans are occupying the photic zones down to about $200 \mathrm{~m}$ from the water surface, and sea bottoms areas adjacent to the shallow coastal water. In the deep-sea zone, there is an existence of entire different life. It is a true fact that the oceans and seas are support system of an extended number of biological diverse species, which are immensely important for the ecological diversity. There are total 222,000 - 230,000 marine species listed, and almost 200,000 belong to Animalia [3]. Marine habitats are fragile because they are highly reactive to the variations and transformation in physical environments [4].

Sensitivity of the biodiversity in fresh water resources is more than any other terrestrial ecosystems [5]. The vulnerability of the freshwater habitat is because disproportionate numbers of plant and animal communities are growing in the water regime. As estimated by Lundberg et al. [6] freshwater bodies are enriched with more than 10,000 fish species, which comprises approximately $40 \%$ of global fish communities and one fourth of diverse vertebrate population at global scale. Combining countless number of amphibians, aquatic reptiles and mammalian populations to the total quantity of freshwater-fish clearly depicts the freshwater habitat as the only favorite biological spot of all vertebrates. Comprehensive information about the total species diversity in the freshwater resources is incom- 
plete especially among invertebrates and microbes and in the tropical zones of the world that serves as a dwelling spot of different species of the world. From amphibian's phylum, total of 5778 species has been identified since last 10 years [7]. Mekong drainage in Cambodia has been identified as one of the global "hotspots" for regional river fish biodiversity; Rainboth [8] estimated that Mekonge basin has variety of species richness making it globally recognized. Recent research estimation has revealed fish wealth of about 1700 species [9]. It has been noticed that freshwater biological regions are given less interests than terrestrial zones [10]. Documentation about invertebrate animals diversity in tropical freshwaters are not available. However, great endemism and species richness at regional habitat do exist in the groups of crustaceans, mollusks and aquatic arthropods [11] [12] [13]. Information on microbial biodiversity in the freshwater bodies is also not well recorded, not indicating the vital function of microorganisms in biogeochemical cycles operation on the earth. Most of the prokaryotic taxonomic groups are still not discovered [14] [15].

Aquatic biodiversity increases with latitudes with maximum in the tropical zones. The best examples of aquatic ecosystem biodiversity can be seen in the Amazon River. The Great Barrier Reef in Australian continent is the largest coral reef ecosystem in the world, habitat of over 700 varieties of coral, and also giving shelter to diverse varieties of fish and mollusks species. Coral reefs are the systems with extreme biodiversity of marine animals. One studies from the Red Sea region of Gulf of Aqaba, has revealed that egg releasing phase of aquatic animals are different throughout the year in this particular region of marine ecosystem [16]. This gives the strikingly different detail from the Great Barrier Reef, where aquatic animals and coral spawning occurs at the same time [16] [17].

Not only marine systems many fresh-water ecosystems are also a favorable biological spot of unique species, because freshwater habitats are isolated environment on the natural landscape, facing obstacles of distance and weather conditions which is a difficult task to tolerate. Such kind of ecological phenomena favors the evolution of new species in different fresh-water resources.

Hynes [18] categorized a number of diverse plant species found in and around aquatic bodies: flowering plant, mosses, liverworts, species of encrusting lichens, stonewort and other enormously growing algal species. The uninterrupted water cycles in the aquatic bodies have an immense role in the arrival of minerals and nutrient components from high level to low-lying area and eventually to the extended sea and ocean water [19]. Aquatic bodies downstream support a rich diverse species of plants: cool hard bottom streams containing mostly bryophytes and large soft bottom rivers supporting angiosperms. Among macrophytes the plant species, which is most diverse in running water bodies, is the benthic algae. They occur on all possible surfaces along the river and are intimately associated with microbes and an extracellular organic matrix called Aufwuchs (minute plants and animals attached to rooted aquatic plants and other exposed layers, this also collects scrapers who are organisms and detritus covering rocks and plants colonizing the aquatic environment and often serve the purpose of fish food). 
In aphotic zones of the rivers the diatom species abound in large numbers. Large aquatic bodies in the tropics have more species diversity than those in temperate regions; in addition species richness increases rapidly in lower latitudes than higher ones [19]. Flow regimes of running aquatic bodies are important. It adds to the sustaining capability of Rivers and their associated flood plain. Any alteration of flowing stream often claims to be the serious and threatens wetlands and their species diversity.

Many authors have observed the distinction in plant group structure related to spatial and temporal distribution, which has influence of flood and scour, desiccation, substrate stability and localized variations in water velocity, turbulence and shear stress.

Sometimes aquatic flora has isolated or discontinuous growth and availability in the environment because of differences in distribution, frequency and intensity, establishment success and growth rates. Rørslett [20] found that increased stability of base flow and reduction of flow variability led to excessive growths of aquatic macrophytes. Similarly seedling survival and plant growth rates are affected by changes in rates of water level fluctuation and disturbance frequency and intensity [21]. In this review information on biodiversity in aquatic habitats and their resources, in marine and fresh water ecosystems, their importance conservation and restoration mechanisms was discussed in brief.

\section{Role of Biodiversity in the Ecosystem}

Figure 1 represents the vast functions and services provided by the ecosystem biodiversity, which is continuously supporting the mankind and its existence [22].

\section{Threats to Aquatic Biodiversity}

In December 2003, United Nations General assembly, declared the year 2005 to

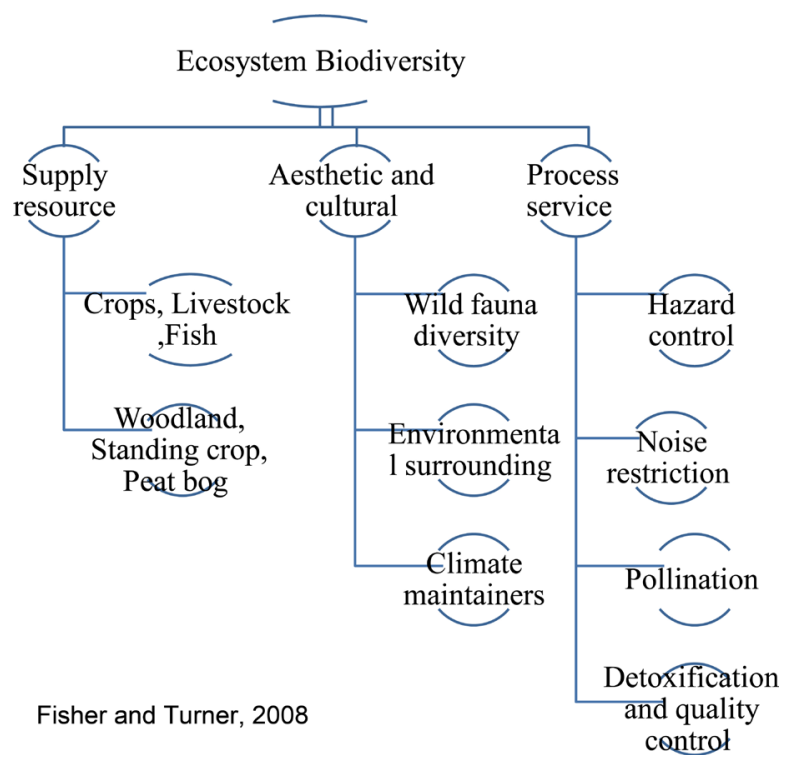

Figure 1. Showing various uses of ecosystem biodiversity. 
2015 as an international year for aquatic life, this official adoption was implemented to control the threats to aquatic biodiversity and their preservation and protection. The resolution demanded the serious concern on global water issues and development attempts, and nations were joined to fulfill the water related targets of the 2000 Millennium declaration. It is important to mention that Agenda 21 from the proposal was taken with grave concern to provide the world's population access to safe drinking water and hygienic sanitation, which is accepted as the basic right of every citizen of the world [21]. "Water for Life" resolution of United Nations was implemented at the same time when the biodiversity and biological resources of the aquatic resources were under the threats of anthropogenic activities. The threats to global aquatic biodiversity are very clearly known and the reasons can also be perceived; yet the extent of these damages varies from region to region. Identifying these threats can have little effect on the conservation, so it is advisable to mitigate the threats that can be a practical approach towards restoration.

Since long time the Red Sea has been given the status of high marine biodiversity spot [23] and endemism [10], which is an ecological niche of more than 1000 species of fishes and over 50 genera of reef forming (hermatypic) corals. Recently project studies have shown the possibility of extinction of many large fishes in Saudi Arabian Red sea coral reefs ecosystem, but some of the predator fishes can still be conserved if Saudi's Red sea reefs are restored to the original condition [24]. Marine ecosystem of the Red Sea is an extensive area of coral reefs, where numerous numbers of diverse endemic species are thriving. Communities of Sea grasses, meadows and mangroves systems are also depending on the Red Sea. This zone of marine ecosystem is facing a pressure from fishing, shipping, oil industry, aquaculture, marine water desalination, urban and industrial discharge, plastic wastes, human activities and climate difference.

Trinidad and Tobago adequate freshwater resource ecosystems were under continuous threats and the damages to the freshwater habitats was noticeable [25]. Important significant impacts that were causing extensive damage to the water resources and the loss of aquatic biodiversity are deforestation, use of pesticides in agriculture and water for irrigation purpose, rise in urban and industrial sector, regulation of water for dam and hydroelectricity production, mineral and petroleum extraction, Solid wastes dumps, bottom dredging and water flow channelization, fishing and aquarium market [26]. According to Olsen et al. [27] Trinidad and Tobago's freshwater ecosystems has a significant local value as biologically distinguished system, but seriously at the risk of extinction in terms of conservation category. All these freshwater systems were included in the priority list of conservation at the regional basis. In Chile, freshwater resource protection was targeted towards habitat protection to conserve the exotic species of Salmonids. This biodiversity management in turn benefited the balance of ecosystem process and preservation of indigenous fauna [28] [29]. The similar situation happened in the New Zealand also, where conservation of Salmonids and other valuable fish biodiversity has made great impact on the development of habitat 
protection [30].

Colonization of new species in the aquatic system through human activities, whether knowingly or unknowingly, is becoming global environmental issue. The problem of introduced species is on the rise in United States freshwater resources. In the year 1920, six exotic fishes were introduced into the freshwater; a few more had been added by 1945 and until 1980 more species had been noticed. Newly arrived species in the ecosystem creates many problems for the native species, as they start breeding and population growth in more area other than their particular spot. Removal of chemical contaminations from the aquatic ecosystem can be eliminated at the point of source, or the habitat can be restored after pollution peak, but once the species introduction has begun, it is very difficult to reverse this task of introduction. Besides this introduced or alien species can also produce negative impacts on native organism of the water resources, such as preying of animals, competition, niche alteration, interspecific breeding, and disease and parasitic infection development. Species are introduced to the new environment to gain economic advantage or to fulfill the developmental requirements like aquaculture. This introduction can be economically profitable initially but later it can produce disadvantages on economical and ecological terms, due to their invasive growth. Such an example is of Oysters, which has been introduced in to the global coastal waters for food. Oysters have function in estuarine ecosystem brings several complex modifications. Apart from this when oysters combine with alien oysters they get attached to their shells creating a kind of mismanagement in the aquatic system [31]. Introduced invasive species in the marine environment are a severe threat to biodiversity of the ecosystem because of their prolific growth and other harmful effects creating ecological and economical disruption.

1) Overexploitation of species: over exploitation of particular species to fulfill the demand of human greed can result in the loss of genetic diversity and that lowers the relative species abundance of individual or groups of interacting species. This process can reduce the population size as a result of interruption in age structure and sex composition. Fishing exploitation disrupts the genetic constitution of fish population because of loss of some alleles from the genome, reducing the genetic diversity.

2) Habitat modification: structural modification in the habitat may also bring species extinction for example, dam construction, deforestation, diverting water course for agriculture supply changing marsh land and small water entities for other function. Building dams on river obstructs the migration of fishes from the source point and cause movement of populations from their natural spawning area and divides the population in to smaller groups. Another instance is outcome of deforestation that leads to progressive degradation of catchment area due to soil erosion causing sedimentation and siltation. This process has negative impact not only on the breeding zone of aquatic organisms but also results in blockage of gills in small fishes. 
3) Organic pollutants drainage/suspended solids/sewage discharge: this includes toxic and poisonous compounds like metals, agrochemical substances, phenolic and acidic discharge, promoting mortality rate and suppresses the reproductive function of the aquatic animals [32]. Suspended solids create problems and suffocation in respiration physiology and production of mucus that makes the fishes prone to infections produced by aquatic pathogens. Discharge of sewage results in eutrophic aquatic system, causing deoxygenation and aggravates death rate in aquatic organism and submerged aquatic flora.

4) Thermal pollution: produce changes in surrounding water temperature and reduces the concentration of dissolved oxygen in the water column consequently death of small and sensitive aquatic animals. Death rate acceleration in the aquatic organisms affects the aquatic biodiversity either by promoting extinction of species or population or reduced population. Remarkable rise in ocean water temperature due to marked El Niño phenomenon has anxious the scientists who noticed the coral bleaching could extend beyond 2017 [33]. Climate change and global warming has been accepted as the main reason behind rise in ocean water temperature, which now threatening the rich but vulnerable wealth of coral reef's worldwide [34].

\section{Conservation Approaches for the Aquatic Ecosystems}

One of the remarkable approach especially for the conservation of aquatic ecosystems was United Nations Convention on the Law of Sea (UNCLOS) which was implemented in the year 1994. This law was basically considering the promotion and support of the biodiversity along with the sustainable use of the oceanic water. Major non-government international organizations, research institutes and scientific groups can collaborate under the roof of the United Nations to work together for the assessment of global biodiversity and identification and listing of hotspots as biodiversity indicator. However, to prevent the future losses in the biodiversity either marine or freshwater, inadequate information availability should not be considered as hindrance in the progress of conservation. Communities operating at the broader sector should not delay waiting for the right time to get all the potential facts to initiate any process. Some of the data collected in the class of fishes and marine reptiles and other taxa are sufficient and reliable to trust that aquatic biodiversity is going through the crisis and can be calamity if not prevented.

Charles Elton, the "father of ecology", once presented his idea of conservation in his words that we should be "... looking for some wise principle of co-existence between man and nature, even if it has to be a modified kind of man and a modified kind of nature. This is what I understand by conservation" [35]. Rosenzweig [36] also favored the idea of reconciliation ecology, suggesting different species inhabitation together with mankind to enhance species richness and positive outcome. Many wetland zones, whether fresh or brackish-water are biologically engineered by man or the environment is controlled by man. The best 
example is represented at Ramsar site, which hosts a large number of water birds which are under serious threats of extinction, another wetland in Indian subcontinent known as "Kabar Taal" is a winter niche for many migratory birds. Both these examples clearly show that human alterations in the ecosystem can be compatible and cooperative in biodiversity conservation.

It has been recommended that strategies to conserve aquatic resources should comply with ecosystem conservation, which can favor the growth of biotic resources, and help to maintain the natural habitats and ecosystems (Figure 2). In order to make aquatic biodiversity conservation effective and successful, conservation management regulations should include all broad areas.

- Aquatic regions suffering from anthropogenic destruction, degradation or habitat loss should be aimed for the restoration. The same objective should imply for the conservation of the plant or animal species, which are facing decline growth and are close to extinction from the community. Water systems and aquatic biodiversity are closely related and interdependent on each other. General assumption is that water quality and habitat quality have an effect on the species composition, diversity and physical structure of the aquatic ecosystems [37].

- Bio-reserve spots can be created within a water body where fishing is restricted along with the other activities to protect the plants, animals and their habitat to conserve the aquatic biodiversity. Another useful role of these bioreserves are that they can be highly beneficial for the purpose of education, recreation, tourism as well as potential increase in fishes reserve by improving the conditions of declining fish population. These bio-reserves function as marine protected areas, fishery reserves, sanctuaries and biological parks.

- Bioregional management, can help to regulate factors influencing aquatic biodiversity, brings the balance in conservation, economy, and social demand of an area. This includes biosphere zones from small area and larger reserves. Figure 2 sketching the network of global biodiversity monitoring system and regional areas protection plan. Red Sea Biodiversity joint project was conducted to assess the marine biodiversity of the Saudi-Arabian coast and deep water of the Red Sea and to create an information source at the King Abdul Aziz Marine Museum (KAUMM) and at Senckenberg

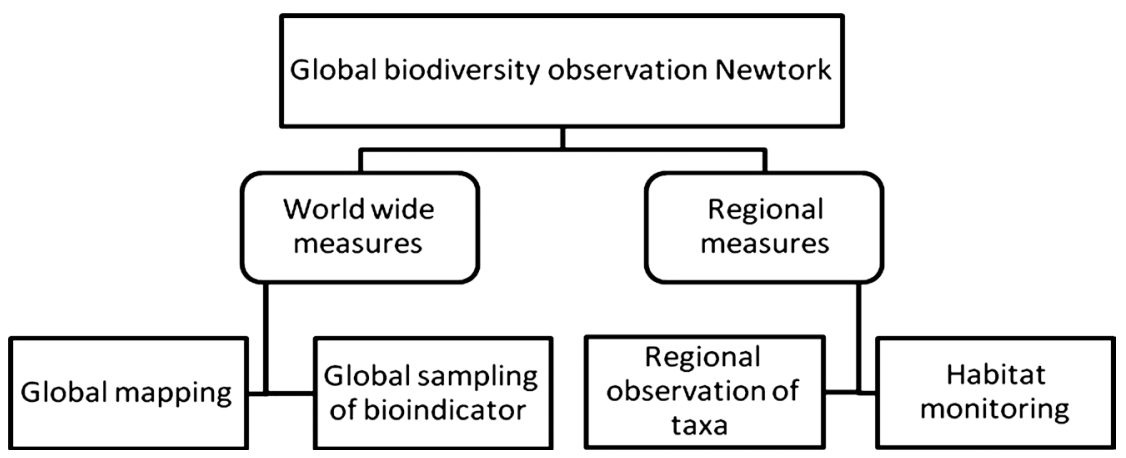

Figure 2. Representation of global biodiversity monitoring system. 
Biodiversity Research Institute in Frankfurt am Main, Germany (SRI) in 2011. This project programme was aimed at the collection and identification of species of all marine animal groups. Marine species were preserved and catalogued as a reference source of the KAUMM and SRI [38].

- Watershed management has a significant role in keeping the balance and preservation of aquatic diversity. Aquatic resources are open and unprotected system, because their geographical route often crosses through many political territories. Such type of situation creates difficulty in conservation and management of resources. However, recently, this situation has improved as regional and local watershed communities have started protection projects for lakes and streams. The Napo drainage depression of the Amazon basin is enormously biodiverse ecosystem located in Ecuador, has gone through the various anthropogenic threats. Lessmanna et al., [39] enlisted the freshwater vertebrates and invertebrates, and also prepared their diversity and distribution model. The study was focused on the freshwater invertebrate and vertebrate taxa. Species richness maps were prepared using compilation data for approximately 481 freshwater vertebrate species, which includes amphibians, birds, mammals, reptiles and fishes and over 54 invertebrate families recorded from the altitude of $200-4500 \mathrm{~m}$ height of the basin. The interest of the study was to implement conservation and management programs for the high species diversity of invertebrates in the large tropical Napo basin with the help of manpower, financial expenditure, human attempt, skilled knowledge and time [39].

- Afforestation around drainage or catchment area of water bodies can control soil erosion and helps to minimize sedimentation in the water systems. This can provide better survival environment to aquatic fauna.

- Construction of industeries, chemical factories and thermal power plants adjacent to the aquatic systems should be controlled as industrial effluent can damage the environment supporting aquatic ecosystem and finally results in the loss of biodiversity.

- The World Resources Institute USA, which is a global research organization, has emphasized the idea of putting particular plant or animal in threatened or endangered category can be helpful in protecting the biodiversity. Restoration of the aquatic resources can also be promoted via specialized educational programme. For example, USDA Forest service has begun a special course with target to protect and restore the river ecosystem and their related species. Several international universities also offer the biodiversity conservation management program, to create understanding and awareness about significance of biodiversity among upcoming generation.

- Regulation of industrial and urban wastewater discharge must be taken in to consideration to conserve the aquatic resource diversity.

- Spreading awareness at the social forum is the friendliest way to educate the community about conservation of aquatic biodiversity. This can be achieved successfully via educational programs, prize sponsored events, and volunteer 
promotions.

- Marine protected areas-developments of Marine protected areas (MPAs) are receiving popularity as a coral reef management tools for the management of coral reef systems [40] [41]. Non-coral invertebrates also contribute in providing enormous biodiversity to coral reef ecology, but their role in the marine ecosystem is still not well explored [42]. Japan has been designating Marine Protected Areas since long time. Examples of them are 1) Natural Parks and Natural Seashore Conservation Areas that aim to protect the natural landscape 2) Nature Conservation Areas, Wildlife Protection Areas, Natural Habitat Conservation Areas and designated areas for natural monuments for the protection of the natural environment or the habitat of organisms; and 3) Protected Water Surface zone aim towards conservation and gardening of aquatic animals and plants, coastal marine resource development areas and other various specified areas designated by different entities such as prefectural governments and fishing groups [43].

\section{Conclusion}

Scientific reports have shown that habitats having extended biodiversity have chances to adapt in the new environment and regrow from various disasters either anthropogenic or natural. This can be considered beneficial in support of biodiversity since different species are performing the similar functions in a biologically diverse ecosystem, a disruption affecting one species may produce little impact on the entire ecosystem. Habitats with little diversity are considered as more vulnerable, as any insignificant interference in one species life may cause negative impact on the complex of interactions to collapse. Public awareness is demand of the time to teach citizens that only healthy functional aquatic ecosystems can provide all the benefits of improved water quality, water production and biodiversity richness. Immediate action in the form of strategic plans, economic incentives, public awareness and stakeholder involvement should be taken for the management and restoration of water resources and aquatic ecosystems. The management of water resources and aquatic ecosystems needs proper land management and sustainable implementation of land practices and holistic sense to identify the relevance between natural and manmade effects and developments. With the increase in population and human activities there will be more utilization of water resources so their biodiversity. Hence, restoration of aquatic habitat and conservation of biodiversity is the need of this modern time to maintain the quality of life.

\section{Conflicts of Interest}

The authors declare no conflicts of interest regarding the publication of this paper.

\section{References}

[1] Postel, S. and Richter, B. (2012) Rivers for Life: Managing Water for People and 
Nature. Island Press, Washington.

[2] Gleick, P.H. (1996) Water Resources. In: Schneider, S.H., Ed., Encyclopedia of Climate and Weather, Oxford University Press, New York, 817-823.

[3] Appeltans, W., Ahyong, S.T., Anderson, G., Angel, M.V., Artois, T., Baily, N., et al. (2012) The Magnitude of Global Marine Species Diversity. Current Biology, 22, 2189-2202. https://doi.org/10.1016/j.cub.2012.09.036

[4] Pan, J., Marcoval, M.A., Bazzini, S.M., Vallina, M.V. and De Marco, S.G. (2013) Coastal Marine Biodiversity Challenges and Threats. CRC Press, Boca Raton, 43-67.

[5] Roberto, C.G. (2016) Freshwater Biodiversity: A Review of Local and Global Threats. International Journal of Environmental Studies, 73, 887-904. https://doi.org/10.1080/00207233.2016.1204133

[6] Laundbrg, G., Kottelat, M., Smith, G.R., Undberg, G., Kottelat, M., Smith, G.R., Stiassny, M.L.J. and Gill, A.C. (2000) So Many Fishes, So Little Time: An Overview of Recent Ichthyological Discovery in Continental Waters. Annals of the Missouri Botanical Gardens, 87, 26-62. https://doi.org/10.2307/2666207

[7] Amphibia Web (2005) Amphibia Web Species Numbers. AmphibiaWeb: Information on Amphibian Biodiversity and Conservation. Berkeley. http://amphibiaweb.org/

[8] Rainboth, W.H. (1996) Fishes of the Cambodian Mekong. Food and Agriculture Organization of the United Nations (FAO), Rome.

[9] Sverdrup-Jensen, S. (2002) Fisheries in the Lower Mekong Basin: Status and Perspectives. MRC Technical Paper No. 6, Mekong River Commission, Phnom Penh.

[10] Myers, N., Mittermeier, R., Mittermeier, G.C., Dafonseca, G.A.B. and Kent, J. (2000) Biodiversity Hotspots for Conservation Priorities. Nature, 403, 853-858. https://doi.org/10.1038/35002501

[11] Benstead, J.P., De Rham, P.H., Gatolliat, J.L., Gibon, F.M., Loiselle, Sartori, M., Sparks, J.S. and Stiassny, M.L.J. (2003) Conserving Madagascars Freshwater Biodiversity. Biological Science, 53, 1101-1111.

[12] Strayer, D., Downing, J.A., Haag, W.R., King, T.L., Layer, J.B., Newton, T.J. and Nichols, S.J. (2004) Changing Perspectives on Pearly Mussels, North America's Most Imperiled Animals. Biological Science, 54, 429-439. https://doi.org/10.1641/0006-3568(2004)054[0429:CPOPMN]2.0.CO;2

[13] Dieter, H. and Cameron, H. (2014) Nature in the Balance: The Economics of Biodiversity. Oxford University Press, Oxford.

[14] Torsvik, V., Øvreas, L. and Thingstad, T.F. (2002) Prokaryotic Diversity Magnitude, Dynamics, and Controlling Factors. Science, 296, 1064-1066.

https://doi.org/10.1126/science.1071698

[15] Curtis, T.P. and Sloan, W.T. (2004) Prokaryotic Diversity and Its Limits: Microbial Community Structure in Nature and Implications for Microbial Ecology. Current Opinion in Microbiology, 7, 221-226. https://doi.org/10.1016/j.mib.2004.04.010

[16] Shlesinger, Y., Goulet, T. and Loya, Y. (1998) Reproductive Patterns of Scleractinian Corals in the Northern Red Sea. Marine Biology, 132, 691-701. https://doi.org/10.1007/s002270050433

[17] Berumen, M.L., Hoey, A.S., Bass, W.H., Bouwmeester, J., Catania, D., Cochran, J.E.M., Khalil, M.T., Miyake, S., Mughal, M.R., Spaet, J.L.Y. and Saenz-Agudelo, P. (2013) The Status of Coral Reef Ecology Research in the Red Sea. Coral Reef, 32, 737-748. https://doi.org/10.1007/s00338-013-1055-8

[18] Hynes, H.B.N. (1970) Ecology of Running Waters. University of Toronto Press, 
Toronto.

[19] Kearns, C. (2010) Conservation of Biodiversity. Nature Education Knowledge, $3,7$.

[20] RФrslett, B. (1989) An Integrated Approach to Hydropower Impact Assessment. II Submerged Macrophytes in Some Norwegian Hydroelectric Lakes. Hydrobiologia, 175, 65-82. https://doi.org/10.1007/BF00008476

[21] Dudgeon, D., Arthington, A.H., Gessner, M.O., Kawabata, Z.-I., Knowler, D.J., Leveque, C., Naiman, R.J., Prieur-Richard, A.H., Soto, D., Stiassny, M.L.J. and Sullivan, C.A. (2006) Freshwater Biodiversity: Importance, Threats, Status and Conservation Challenges. Biological Review, 8, 163-182. https://doi.org/10.1017/S1464793105006950

[22] Fisher, B. and Turner, R.K. (2008) Ecosystem Services: Classification for Valuation. Biological Conservation, 141, 1167-1169. https://doi.org/10.1016/j.biocon.2008.02.019

[23] Di Battista, J.D., Roberts, M.B., Bouwmeester, J., et al. (2016) A Review of Contemporary Patterns of Endemism for Shallow Water Reef Fauna in the Red Sea. Journal Biogeography, 43, 423-439. https://doi.org/10.1111/jbi.12649

[24] Kattan, A., Coker, D.J. and Berumen, M.L. (2017) Reef Fish Communities in the Central Red Sea Show Evidence of Asymmetrical Fishing Pressure. Marine Biodiversity, 47, 1227-1238. https://doi.org/10.1007/s12526-017-0665-8

[25] Water Resources Agency (WRA) (2001) Water Resources Assessment Report 1988/98. Water Resources Agency, Trinidad.

[26] Humbert, J.F. and Dorigo, U. (2005) Biodiversity and Aquatic Ecosystem Functioning: A Mini-Review. Aquatic Ecosystem Health and Management, 8, 367-374. https://doi.org/10.1080/14634980500457773

[27] Olsen, D., Dinerstein, E., Canevari, P., Davidson, I., Castro, G., Morisset, V., Abell, R. and Toledo, E. (1998) Freshwater Biodiversity of Latin America and the Caribbean: In A Conservation Assessment. Biodiversity Support Program, Washington DC.

[28] Craig, R.K. (2012) Marine Biodiversity, Climate Change, and Governance of the Oceans. Diversity, 4, 224-238. https://doi.org/10.3390/d4020224

[29] Mc Clenachan, L., Cooper, A.B., Carpenter, K.E. and Dulvy, N.K. (2012) Extinction Risk and Bottlenecks in the Conservation of Charismatic Marine Species. Conservation Letters, 5, 73-80. https://doi.org/10.1111/j.1755-263X.2011.00206.X

[30] Anon (2003) Protecting Lake Taupo. A Long Term Strategic Partnership. Environment Waikato, Hamilton.

http://www.ew.govt.nz/policyandplans/taupo/documents/index3.pdf

[31] Ruesink, J.L., Lenihan, H.S., Trimble, A.C., et al. (2005) Introduction of Non-Native Oysters: Ecosystem Effects and Restoration Implications. Annual Review Ecological Evolution Systematics, 36, 643-89. https://doi.org/10.1146/annurev.ecolsys.36.102003.152638

[32] Kime, D.E. (1995) The Effects of Pollution on Reproduction in Fish. Reviews Fish Biology and Fisheries, 3, 52-96. https://doi.org/10.1007/BF01103366

[33] Ezzat, L. and Courtial, L. (2016) Coral Bleaching an Imminent Threat to Marine Biodiversity. Ocean-Climate.org, 40-44.

[34] Hoegh-Guldberg, O. and Ridgway, T. (2016) Coral Bleaching Hits Great Barrier Reef as Global Temperature Soar. Green Left Weekly, 10.

[35] Elton, C.S. (1958) The Ecology of Invasions by Animals and Plants. Methuen, London. https://doi.org/10.1007/978-1-4899-7214-9 
[36] Rosenzweig, M.L. (2003) Reconciliation Ecology and the Future of Species Diversity. Oryx, 37, 194-205. https://doi.org/10.1017/S0030605303000371

[37] Revenga, C., Campbell, I., Abell, R., De Villiers, P. and Brayer, M. (2005) Prospects for Monitoring Freshwater Ecosystems towards the 2010 Targets. Philosophical Transactions of the Royal Society B, 360, 397-413. https://doi.org/10.1098/rstb.2004.1595

[38] Sonnewald, M. and El-Sherbiny, M.M. (2017) Editorial: Red Sea. Biodiversity, 47, 991-993. https://doi.org/10.1007/s12526-017-0648-9

[39] Lessmanna, J., Guayasamina, J.M., Casnere, K.L., Fleckerf, A.S., Funke, W.C., Ghalambore, C.K., Gille, B.A., Jácome-Negreteg, I., Kondratieffe, B.C., Poffe, L.N., José Schreckingera, S.A., Thomash, S.A., Toral-Contrerasb, E., Zamudiof, K.R. and Encaladaa, A.C. (2016) Freshwater Vertebrate and Invertebrate Diversity Patterns in an Andean-Amazon Basin: Implications for Conservation Efforts. Neotropical Biodiversity, 2, 99-114. https://doi.org/10.1080/23766808.2016.1222189

[40] Mora, C., Andrefouet, S., Costello, M.J., Kranenburg, C., Rollo, A., Veron, J., Gaston, K.J. and Myers, R.A. (2006) Coral Reefs and the Global Network of Marine Protected Areas. Science, 312, 1750-1751. https://doi.org/10.1126/science.1125295

[41] Almany, G., Connolly, S., Heath, D., Hogan, J., Jones, G., McCook, L., Mills, M., Pressey, R. and Williamson, D. (2009) Connectivity, Biodiversity Conservation and the Design of Marine Reserve Networks for Coral Reefs. Coral Reefs, 28, 339-351. https://doi.org/10.1007/s00338-009-0484-x

[42] Bouchet, P., Lozouet, P., Maestrati, P. and Heros, V. (2002) Assessing the Magnitude of Species Richness in Tropical Marine Environments: Exceptionally High Numbers of Molluscs at a New Caledonia Site. Biological Journal Linnean Society, 75, 421-436. https://doi.org/10.1046/j.1095-8312.2002.00052.x

[43] Marine Biodiversity Conservation Strategy (2011) Development of Measures for Conservation and Sustainable Use of Marine Biodiversity. Ministry of Environment Report, 34. 